Rountree, P. M. (1956). J. gen. Microbiol. 15, 266-279

\title{
Variations in a Related Series of Staphylococcal Bacteriophages
}

\author{
BY PHYLLIS M. ROUNTREE \\ Fairfax Institute of Pathology, Royal Prince Alfred Hospital, Sydney, \\ New South Wales, Australia
}

\begin{abstract}
SUMMARY: Stocks of staphylococcal phage 47C (serological group A) contained some group B phage. This was found to have originated in a lysogenic staphylococcus previously used to propagate phage $47 \mathrm{C}$ and which had subsequently lost its lysogenicity. The lysogenic phage was thus perpetuated in the phage stocks as a lytic phage. The characters of the two phages are described. When they lysogenized five different strains of staphylococci changes in typing pattern were produced. There was evidence which indicated that, in the prophage state, the two phages occupy different sites and that there is no cross-immunity between them. The propagation of the phages in different hosts resulted in changes in their host range. A virulent mutant of the B prophage was induced by the application of a variety of phages to the strain carrying it.
\end{abstract}

Since the introduction of staphylococcal phage typing (Fisk, 1942; Wilson \& Atkinson, 1945) one method of preparing new phages has been by 'adaptation'. A staphylococcus not lysed by any of the typing phages at their routine test dilution may show plaques when tested with an undiluted phage; the phage thus revealed can then be propagated to high titre on the previously untypable strain. This 'adapted' phage may be a lysogenic contaminant derived from the strain used to propagate the original phage, and thus have no relationship to the phage from which it has been 'adapted'. Such was the origin of phage $42 \mathrm{C}$ (Rountree, $1949 a$ ). Since nearly all strains of Staphylococcus aureus are lysogenic (Rountree, 1949b), contaminating lysogenic phage may be the origin of many 'adapted' phages. However, the behaviour of other phages such as the typhoid Vi phages (Anderson \& Felix, 1953) suggests that phenotypic variation and genetic mutation should also be considered as possible mechanisms of the origin of staphylococcal phages with altered host ranges or antigenic structure. Rippon (1952) described mutation of antigenic structure from group $\mathrm{B}$ to group $\mathrm{F}$ in the staphylococcal typing phage $42 \mathrm{D}$. Ralston \& Krueger (1954) produced evidence of phenotypic variation in host range of phage $\mathbf{K}$ (not a typing phage) dependent on the host used for its propagation.

During phage typing of staphylococci the application of a phage results, on occasion, in an area of confluent lysis covered with a thin veil of secondary growth which contains a few plaques larger in size than those of the phage originally applied. This appearance was noted frequently with phage $47 \mathrm{C}$ and, on isolation, phage from the large plaque was found to belong to serological group $\mathrm{B}$, whereas $47 \mathrm{C}$ is group $\mathrm{A}$ (Rountree, $1949 \mathrm{~b}$ ). The origin of this group B phage was therefore investigated. During subsequent work, the use of a number of different hosts for the propagation of phage $47 \mathrm{C}$ and of the group $\mathrm{B}$ phage 
revealed examples of changes in host range which appeared to be due to phenotypic variation. In addition, a virulent mutant of the group $B$ phage was isolated. The typing patterns of various host staphylococci were altered by lysogenization with the two phages.

\section{METHODS}

Phage stocks were prepared either in broth or on agar by methods described previously (Rountree, 1949b, 1952). Phage counts were made in quadruplicate by plating $0.01 \mathrm{ml}$. samples of the appropriate dilution on the surface of nutrient agar plates previously flooded with the appropriate propagating strain of staphylococcus.

The host range of the phage was examined in the first place by the method of Williams \& Rippon (1952) using the propagating strains of staphylococci of Wilson \& Atkinson (1945). More accurate determinations of host range were made by counting the number of plaques produced by a phage on all the strains sensitive to it. Strains of staphylococci were tested for lysogenicity by growing them in nutrient broth at $37^{\circ}$ for $2-3 \mathrm{hr}$., centrifuging (angle centrifuge) and plating the supernatant fluids on appropriate indicator strains.

Phage neutralization tests with antisera prepared in rabbits were incubated at $37^{\circ}$ for $90 \mathrm{~min}$. before plating.

Staphylococci. Five staphylococcal strains were used to propagate phage 47 C. Staphylococcus $1163 \mathrm{~Pa}$ was obtained from the Staphylococcal Reference Laboratory, Colindale, London, in 1946, and has been maintained since then on agar slopes and used as the propagating strain for phages $42 \mathrm{~B}$ and $47 \mathrm{C}$. Staphylococcus $1163 \mathrm{Col}$ is another culture of strain 1163 obtained from Colindale in April 1953. These strains will be referred to as $\mathrm{Pa}$ and Col. Staphylococcus strains 7104, 7167 and 7296 were isolated from patients in this hospital. The phage-typing patterns of these strains are shown in Table 1. Since the lysogenic state of the strains was of some significance in the present work, the table includes data on their lysogenicity.

Table 1. The phage-typing patterns and lysogenicity of strains of Staphylococcus aureus used to propagate phage $47 \mathrm{C}$

\begin{tabular}{|c|c|c|c|}
\hline \multirow[b]{2}{*}{ Strain } & \multirow[b]{2}{*}{ Phage pattern } & \multicolumn{2}{|c|}{ Character of lysogenic phage present in strain } \\
\hline & & Serological type & $\begin{array}{l}\text { Strains lysed by } \\
\text { the phage }\end{array}$ \\
\hline $\mathbf{P a}$ & $42 \mathrm{~B} / 47 \mathrm{C} / 52$ & - & - \\
\hline Col & $42 \mathrm{~B} / 47 \mathrm{C}$ & $\mathbf{B}$ & $\begin{array}{c}6,7,31 / 44,44 \mathrm{~A} \\
47, \mathrm{~Pa}, 7296\end{array}$ \\
\hline 7104 & $29 / 42 \mathrm{~B} / 47 \mathrm{C}$ & $\mathbf{B}$ & $31 / 44,47$ \\
\hline 7167 & $29 / 42 \mathrm{~B} / 47 \mathrm{C} / 52 / 52 \mathrm{~A}$ & $\mathbf{B}$ & $\begin{array}{c}6,7,31 / 44,42 \mathrm{C}, 42 \mathrm{E} \\
44 \mathrm{~A}, 47,7296\end{array}$ \\
\hline 7276 & $\begin{array}{c}6 / 7 / 31 \mathrm{~B} / 42 \mathrm{~B} / 42 \mathrm{E} / 44 / 47 / 47 \mathrm{C} / \\
47 \mathrm{D} / 52 / 52 \mathrm{~A} / 53 / 54 / 75\end{array}$ & Not $A, B, F$ or $G$ & 6,47 \\
\hline
\end{tabular}

Phages. Phage 47 C was obtained from Colindale in 1946. The stock used as the starting material for the present work was made in broth in December 1952, 
using strain $\mathrm{Pa}$ for propagation. Phage stocks are designated by the number or letter of that strain followed by that of the strain on which it was propagated. e.g. phage $\mathrm{Col} / \mathrm{Pa}$ is a lysogenic phage from propagating strain $\mathrm{Col}$ grown in propagating strain $\mathrm{Pa}$. When strains have been lysogenized the presence of the lysogenic phage is indicated in parentheses after the strain number or letter, e.g. strain $\mathrm{Pa}(47 \mathrm{C})$ carries phage $47 \mathrm{C}$.

\section{Origin of the group $B$ phage present in stocks of $47 \mathrm{C} / \mathrm{Pa}$}

Phage 47 C/Pa produced equal numbers of plaques when plated on propagating strains $\mathrm{Pa}, \mathrm{Col}, 7104$ or 7167 and slightly fewer plaques on strain 7296 . The group B phage present in the stock phage could be detected only on strains $\mathrm{Pa}$ and 7296, on which it appeared as large plaques in the secondary growth covering the area of confluent lysis produced by undiluted and $10^{-1}$ dilutions of phage $47 \mathrm{C}$. Strain $\mathrm{Pa}(47 \mathrm{C})$ could also be used to count the $\mathrm{B}$ phage.

Seven stocks of phage $47 \mathrm{C} / \mathrm{Pa}$ prepared either in broth or on agar using customary inocula of $1 / 20$ or $1 / 100$ dilutions of the stock phage contained $B$ phage in ratios of one $B$ particle to $10^{5} \mathrm{~A}$ particles. Such ratios suggested the possibility of a mutation of $\mathbf{A}$ to $\mathrm{B}$.

Using single plaques from plates inoculated with a $10^{-5}$ dilution of phage $47 \mathrm{C} / \mathrm{Pa} 28$ stocks were prepared. The use of this limiting dilution should ensure that these stocks originated from single particles of A phage. The contents of single plaques when picked into $0 \cdot 1-0 \cdot 2 \mathrm{ml}$. broth and then spread on plates flooded with propagating strain $\mathrm{Pa}$ produced confluent or semi-confluent lysis. Preparations from these plates contained $10^{8}-10^{10}$ particles A phage/ $\mathrm{ml}$. B phage was detected in only one preparation which contained $6 \times 10^{9}$ A particles $/ \mathrm{ml}$. and $1.5 \times 10^{6} \mathrm{~B}$ particles $/ \mathrm{ml}$. This relatively high titre of B suggested that the stock had been made from a mixed plaque resulting from the chance juxtaposition of the two types of particle during the original dilutions and plating of the phage. The absence of phage $\mathbf{B}$ from the other 27 indicated that it was unlikely that its occurrence was due to a mutation of antigenic structure.

Propagating strains $\mathrm{Pa}$ and Col were examined for lysogenicity. While strain Col released into broth large amounts of a $\mathrm{B}$ phage which lysed strain $\mathrm{Pa}$, no lysogenic phage was detected in strain $\mathrm{Pa}$, in spite of repeated testing. When phage from a single plaque of phage $47 \mathrm{C} / \mathrm{Pa}$ was propagated on strain Col the resultant preparation contained a high titre of $A$ and a small amount of B. Propagating strain $\mathrm{Pa}$ could be lysogenized with the $\mathrm{B}$ phage from strain Col and was then resistant to that phage. When typed propagating strain $\mathrm{Pa}(\mathrm{Col})$ gave the same typing pattern as strain $\mathrm{Col}$, its sensitivity to phage 52 being abolished.

A further culture of staphylococcus 1163, obtained from Dr R. Wahl (Institut Pasteur, Paris) who had received it from Colindale in 1948, was lysogenic for a phage identical with that present in propagating strain Col. Furthermore, staphylococcus 1163 was known to have been lysogenic at Colindale in 1948 (Rountree, 1949b). 
It was concluded that the presence of the $B$ phage in stocks of phage $47 \mathrm{C} / \mathrm{Pa}$ could be explained on the assumption that it was lysogenic phage from propagating strain Col. As some time after its arrival in our laboratory our strain of staphylococcus 1163 had lost its lysogenicity and its lysogenic phage was then perpetuated in stocks of phage $47 \mathrm{C}$ as a lytic phage. All stocks of phage $47 \mathrm{C}$ made in propagating strain $\mathrm{Col}$ and in strain $\mathrm{Pa}(\mathrm{Col})$ contain small amounts of the $\mathrm{B}$ phage as a contaminant, but pure stocks of $47 \mathrm{C}$ can be made in propagating strain $\mathrm{Pa}$.

\section{Characters of the phages $47 \mathrm{C} / \mathrm{Pa}$ and $\mathrm{Col} / \mathrm{Pa}$}

When propagated in staphylococcus strain $\mathrm{Pa}$, the two phages displayed differences in plaque size, adsorption constants in broth (Rountree, 1952), requirements of divalent cations for penetration and growth (Rountree, 1955), length of the minimum latent period and average burst size (Table 2). Their ability to show plaques on a number of indicator strains of staphylococci is given in Table 3 and expressed as: $(a)$ numbers of plaques $/ \mathrm{ml}$; $(b)$ the ratio of plaques $/ \mathrm{ml}$. on propagating strain $\mathrm{Pa}$ to plaques $/ \mathrm{ml}$. on the indicator strain. The values of $(b)$ to the nearest round number provide a convenient means of

\section{Table 2. Characters of staphylococcal phages $47 \mathrm{C} / \mathrm{Pa}$ and $\mathrm{Col} / \mathrm{Pa}$}

Serological group Phage $47 \mathrm{C} / \mathbf{P a}$

Mean plaque size (mm.)

Adsorption constant ( $\mathbf{K})$

Minimum latent period (min.)

Activity of divalent cations in adsorption and penetration

Average burst size

Concentration $\mathrm{CaCl}_{2} / \mathrm{ml}$. for maximum average burst size $(\mu \mathrm{g})$

$\begin{array}{cc}\mathrm{A} & \mathrm{B} \\ 0 \cdot 25 & 0 \cdot 8 \\ 20 \times 10^{-11} \mathrm{~cm}^{3} / \mathrm{min}^{-1} & 53 \times 10^{-11} \mathrm{~cm}^{3} / \mathrm{min}^{-1} \\ 60-65 & 40 \\ \mathrm{Ca}++^{*} & \mathrm{Ca}++ \\ \mathrm{Mg}+ \pm & \mathrm{Mg}+ \\ \mathrm{Sr}+ & \mathrm{Sr}- \\ 16 & 90 \\ 100 & 340\end{array}$

$*+=$ cation active, + \pm and $+=$ cation partially active compared with $\mathrm{Ca},-=$ no activity.

\section{Table 3. Host ranges of phages $47 \mathrm{C} / \mathrm{Pa}$ and $\mathrm{Col} / \mathrm{Pa}$}

Host ranges expressed as $(a)$ plaques $/ \mathrm{ml}$. on strain $\mathrm{Pa}$ and on a series of indicator strains, and $(b)$ ratio of plaques $/ \mathrm{ml}$. on strain $\mathrm{Pa}$ to plaques $/ \mathrm{ml}$. on the particular indicator (IS).

\begin{tabular}{|c|c|c|c|c|}
\hline \multirow[b]{2}{*}{$\begin{array}{l}\text { Indicator strain of } \\
\text { staphylococcus }\end{array}$} & \multicolumn{2}{|c|}{ Phage $47 \mathrm{C} / \mathrm{Pa}$} & \multicolumn{2}{|c|}{ Phage $\mathrm{Col} / \mathrm{Pa}$} \\
\hline & $\begin{array}{c}\text { Plaques/ml. } \\
(a)\end{array}$ & $\begin{array}{c}\text { Ratio: } \mathbf{P a} / \mathbf{I S} \\
(b)\end{array}$ & $\begin{array}{c}\text { Plaques/ml. } \\
\text { (a) }\end{array}$ & $\begin{array}{c}\text { Ratio } \\
(b)\end{array}$ \\
\hline $\mathbf{P a}$ & $1.3 \times 10^{9}$ & 1 & $2.4 \times 10^{8}$ & $\mathbf{1}$ \\
\hline Col & $1 \cdot 1 \times 10^{9}$ & 1 & Nil & \\
\hline 7104 & $1.6 \times 10^{9}$ & 1 & c. $7 \times 10^{6}$ & c. $\mathbf{3 0}$ \\
\hline 7167 & $1.2 \times 10^{9}$ & 1 & c. $7 \times 10^{8}$ & c. $\mathbf{3 0}$ \\
\hline 7296 & $4 \times 10^{8}$ & 3 & $8.5 \times 10^{7}$ & 3 \\
\hline 6 & $6 \times 10^{7}$ & 20 & $1.1 \times 10^{6}$ & 220 \\
\hline 7 & $2.6 \times 10^{6}$ & 500 & $5.9 \times 10^{5}$ & 400 \\
\hline $29 \mathrm{~A}$ & Nil & & $1 \times 10^{4}$ & 24,000 \\
\hline $31 / 44$ & $3 \times 10^{5}$ & 4000 & $6 \times 10^{5}$ & 400 \\
\hline $44 \mathrm{~A}$ & $3 \times 10^{5}$ & 4000 & $2.5 \times 10^{5}$ & 1,000 \\
\hline 47 & $1.8 \times 10^{7}$ & 70 & $1.9 \times 10^{6}$ & 130 \\
\hline
\end{tabular}


comparison of host ranges. The phages were tested with the remainder of Wilson and Atkinson's propagating strains of staphylococci but lysed none of them.

Only minor differences were found in the host ranges of the two phages. Propagating strain $\mathrm{Col}$ was resistant to phage $\mathrm{Col} / \mathrm{Pa}$, and strains 7104 and 7167 were partly resistant, displaying only minute and fuzzy plaques which were impossible to count accurately, whereas phage $47 \mathrm{C} / \mathrm{Pa}$ showed plaques equally well on all three strains of staphylococci. Phage $\mathrm{Col} / \mathrm{Pa}$ produced a small number of plaques on propagating strain $29 \mathrm{~A}$ while no preparations of phage $47 \mathrm{C}$ did so.

The shorter latent period and larger burst size of phage $\mathrm{Col} / \mathrm{Pa}$ compared with phage $47 \mathrm{C} / \mathrm{Pa}$ (Table 2 ) might have been expected to give it a selective advantage when the two phages were growing together in the original stocks of $47 \mathrm{C} / \mathrm{Pa}$. That phage $\mathrm{Col} / \mathrm{Pa}$ did not replace $47 \mathrm{C} / \mathrm{Pa}$ may have been due to the high calcium requirement of the former.

\section{The effect of lysogenization on typing patterns}

The staphylococcal strains Col, Pa, 7104, 7167 and 7296 differ in their typing patterns (Table 1). The lysogenic phages carried by strains Col, 7104, 7167 and 7296 differ in host range, and, in the case of 7269, in serology. Since the difference in typing pattern between propagating strains $\mathrm{Col}$ and $\mathrm{Pa}$ might have been correlated with a lack of lysogenicity of strain $\mathrm{Pa}$, the effect of further lysogenization of the five strains of staphlyococci was studied. The strains to be lysogenized were grown in broth or on agar, together with the appropriate undiluted phage for $24-48 \mathrm{hr}$. at $37^{\circ}$. The resulting resistant growth was subcultured on agar plates and, after incubation, single colonies were picked into broth. These cultures were then tested for changes in phage-typing pattern, for resistance to the phage used for lysogenization and for the presence of this phage in the lysogenic state. In the latter test, the homologous non-lysogenized strain was used as indicator strain in order to avoid confusion of the newly introduced phage with lysogenic phage or phages already present in the strain.

Propagating strain $\mathrm{Pa}$ was lysogenized with phages $47 \mathrm{C}$ and Col separately and by both phages one after the other; the order in which the two phages were introduced made no difference. Propagating strains Col, 7104, 7167 and 7296 were lysogenized with phage $47 \mathrm{C}$. Propagating strains 7104 $(47 \mathrm{C}), 7167$, 7167 (47 C) and 7296 were lysogenized with phage Col. Attempts to lysogenize propagating strain $7296(47 \mathrm{C})$ with phage Col were unsuccessful. All the lysogenized strains were resistant to the phages introduced into them. The effect of lysogenization on their typing patterns is shown in Table 4.

In propagating strains $\mathrm{Pa}$, Col, 7104 and 7167 lysogenization with phage $47 \mathrm{C}$ conferred immunity only to this phage. In propagating strain 7296 (a strain sensitive to an extended range of phages) lysogenization with phage $47 \mathrm{C}$ resulted in resistance to phages $6,7,42 \mathrm{E}, 47,47 \mathrm{D}$ and 54 as well as to phage $47 \mathrm{C}$, all of which are serologically $\mathrm{A}$.

The introduction of phage $\mathrm{Col}$ into propagating strain $\mathrm{Pa}$ resulted in immunity to phage 52, into strain 7104 , in immunity to phage 29 and into 
strain 7167 , in immunity to phages 29,52 and $52 \mathrm{~A}$. In propagating strain 7296, sensitivity to phages $31 \mathrm{~B}, 44,52$ and $52 \mathrm{~A}$ was abolished. It should be noted that phage Col does not lyse the propagating strains of any of these phages, all of which are serologically $\mathrm{B}$. The doubly lysogenic staphylococcal strains $\mathrm{Pa}(47 \mathrm{C}, \mathrm{Col}), 7104(47 \mathrm{C}, \mathrm{Col})$ and $7167(47 \mathrm{C}, \mathrm{Col})$ reacted only with phage $42 \mathrm{~B}$ and were therefore identical in typing pattern with PS $\mathrm{Col}(47 \mathrm{C})$.

Table 4. Effect of lysogenization with phages $47 \mathrm{C}$ and $\mathrm{Col}$ on the typing pattern of strains of Staphylococcus aureus

Strain designation*
Col $(47 \mathrm{C}) *$
$\mathrm{~Pa}(47 \mathrm{C})$
$\mathrm{Pa}(\mathrm{Col})$
$\mathrm{Pa}(47 \mathrm{C}, \mathrm{Col})$
$\mathrm{Pa}(\mathrm{Col}, 47 \mathrm{C})$
$7104(47 \mathrm{C})$
$7104(47 \mathrm{C}, \mathrm{Col})$
$7167(47 \mathrm{C})$
$7167(\mathrm{Col})$
$7167(47 \mathrm{C}, \mathrm{Col})$
$7296(47 \mathrm{C})$
$7296(\mathrm{Col})$

$\quad$ Phage typing pattern
$42 \mathrm{~B}$
$42 \mathrm{~B} / 52$
$42 \mathrm{~B} / 47 \mathrm{C}$
$42 \mathrm{~B}$
$42 \mathrm{~B}$
$29 / 42 \mathrm{~B}$
$42 \mathrm{~B}$
$29 / 42 \mathrm{~B} / 52 / 52 \mathrm{~A}$
$42 \mathrm{~B} / 47 \mathrm{C}$
$42 \mathrm{~B}$
$31 \mathrm{~B} / 42 \mathrm{~B} / 44 / 52 / 52 \mathrm{~A} / 53 / 75$
$6 / 7 / 42 \mathrm{~B} / 42 \mathrm{E} / 47 / 47 \mathrm{C} / 47 \mathrm{D} / 53 / 54 / 75$
Phage reactions abolished by lysogenization $47 \mathrm{C}$ $47 \mathrm{C}$ 52 $47 \mathrm{C} / 52$ $47 \mathrm{C} / 52$ $47 \mathrm{C}$ $29 / 47 \mathrm{C}$ $47 \mathrm{C}$ 29/52/52A 29/47 C/52/52A $6 / 7 / 42 \mathrm{E} / 47 / 47 \mathrm{C} / 47 \mathrm{D} / 54$ $31 \mathrm{~B} / 44 / 52 / 52 \mathrm{~A}$

* The lysogenic phages introduced into the strains are indicated in parentheses.

Lwoff's hypothesis (1953) that the presence of a particular prophage at a specific site in the bacterial cell confers immunity to the homologous infecting phage can explain these results, if it be assumed that the receptor sites for antigenically similar staphylococcal phages are either identical or contiguous, and that the occupation of these sites prevents the replication of related infecting phages. Antigenically and in host range the phages to which immunity is conferred by the prophages of $\mathrm{Col}$ and $47 \mathrm{C}$ fall into two distinct groups. Since both these prophages could be introduced into the five staphylococcal strains used, it can be assumed that each occupies a different site in the lysogenized cells. The phage carried by strains 7296 is antigenically different from both $47 \mathrm{C}$ and $\mathrm{Col}$ and its presence in propagating strains 7296 did not prevent lysogenization with either of these two phages; it can be assumed therefore that it occupies a different site in propagating strain 7296. That the sites involved in lysogenization with and attack by antigenically similar phages may be contiguous rather than identical is suggested by the findings with propagating strains 7104 and 7167. These two strains already carry $B$ prophages, apparently not identical in host range with that of propagating strain Col, and their partial resistance to phage $\mathrm{Col}$ may be due to the presence of these prophages. Nevertheless, they can be lysogenized with phage Col.

\section{Phenotypic modification of phages $47 \mathrm{C}$ and $\mathrm{Col}$}

Modification of phage 47C. Stocks of phage $47 \mathrm{C}$ prepared on agar with propagating strains Col, $\mathrm{Pa}, 7104,7167$ and 7296 as host organisms showed differences in their host ranges when expressed as ratios of plaques on the 
strain used for propagation to plaques on a series of indicator strains. Table 4 shows that the host range of phage $47 \mathrm{C} / \mathrm{Col}$ did not differ essentially from that of phage $47 \mathrm{C} / \mathrm{Pa}$. Phages $47 \mathrm{C} / 7104$ and $47 \mathrm{C} / 7167$ resembled each other but differed from the others. Phage $47 \mathrm{C} / \tau 296$ was unlike the others. The chief differences were: (1) the loss of ability to form plaques on propagating strains $\mathrm{Col}$ and $\mathrm{Pa}$ after propagation of the phage in strains 7104, 7167 and $7296 ;(2)$ the acquisition of ability to form plaques on propagating strains 6 and 47 after propagation in strain 7296.

Table 5. Change in host range with change in propagating strain

$$
\text { of phage } 47 \mathrm{C}
$$

\begin{tabular}{|c|c|c|c|c|c|c|}
\hline \multicolumn{7}{|c|}{ Bacteriophages } \\
\hline & & $47 \mathrm{C} / \mathrm{Pa}$ & $47 \mathrm{C} / \mathrm{Col}$ & $47 \mathrm{C} / 7104$ & $47 \mathrm{C} / 7167$ & $47 \mathrm{C} / 7296$ \\
\hline $\begin{array}{l}\text { Titre/ml. on propa } \\
\text { strain }\end{array}$ & gating & $1.3 \times 10^{9}$ & $5 \times 10^{8}$ & $1 \cdot 3 \times 10^{9}$ & $1.6 \times 10^{9}$ & $3 \cdot 6 \times 10^{9}$ \\
\hline \multicolumn{7}{|c|}{ Ratio: Titre on propagating strain to titre on indicator strain } \\
\hline \multirow[t]{10}{*}{ Indicator strain } & $\mathrm{Pa}$ & 1 & 1 & 46,000 & 48,000 & 560,000 \\
\hline & Col & 1 & 1 & 46,000 & 4,000 & 56,000 \\
\hline & 7104 & 1 & 1 & 1 & 1 & $\mathbf{5 0}$ \\
\hline & 7167 & 1 & 1 & 1 & 1 & 150 \\
\hline & 7296 & 3 & 3 & 200 & 80 & 1 \\
\hline & 6 & 20 & 50 & 130 & 90 & 1 \\
\hline & 7 & 500 & 1,000 & 900 & 2,100 & 3,500 \\
\hline & $31 / 44$ & 4,000 & 2,000 & 1,430 & 2,600 & 3,000 \\
\hline & $44 \mathrm{~A}$ & 4,000 & 32,000 & 4,100 & 4,800 & 1,300 \\
\hline & 47 & 70 & 50 & 110 & 120 & 1 \\
\hline
\end{tabular}

When phage 47 $\mathrm{C} / 7104$ was re-propagated in strain $\mathrm{Pa}$, the phage obtained was identical with $47 \mathrm{C} / \mathrm{Pa}$ and $47 \mathrm{C} / \mathrm{Col}$. Since the original stock of $47 \mathrm{C} / \mathrm{Pa}$ had given the same titre whether plated on propagating strains $\mathrm{Pa}, \mathrm{Col}, 7104$ or 7167 , it was considered that the change after growth in propagating strains 7104 and 7167 probably represented host-controlled modification of the particles rather than selection of mutants.

The change in phage $47 \mathrm{C} / 7104$ was examined on agar plates. After incubation of plates inoculated with propagating strain 7104 and a $10^{-1}$ dilution of phage $47 \mathrm{C} / \mathrm{Pa}$, the entire contents of 10 plaques were each picked into $0.5 \mathrm{ml}$. broth, by using a Pasteur pipette drawn out to a capillary. After thorough mixing, samples were replated on propagating strains 7104 and Col. Table 5 shows the number of phage particles/plaque on the two strains and the ratios between the counts. There was a loss of ability to form plaques on propagating strain Col which varied from plaque to plaque, the ratios ranging from 12:1 to $533: 1$. The plaques on propagating strain Col were (with a few exceptions to be discussed later) minute and difficult to see without a hand-lens. These ratios were lower than that found in the original propagation of phage $47 \mathrm{C} / 7104$, viz. 46,000:1.

The changes in phage $47 \mathrm{C} / 7104$ might be explained on the assumption that there was a gradual loss of ability to attack staphylococcal strains $\mathrm{Col}$ and $\mathrm{Pa}$ after numerous cycles of replication of phage $47 \mathrm{C}$ in the cells of other hosts, such as strains 7104 and 67 . Alternatively, one might postulate that, in the 
successive passages of the phage from cell to cell of strain 7104 which will occur when a high titre phage is prepared by confluent lysis on agar plates, selection of 'fitter' (in the sense of their ability to absorb to, or replicate in, cells of strain 7104) phage particles takes place. In either case, the character of the host cells would direct the change. The differences in ratios between the various plaques and the large stock of phage $47 \mathrm{C} / 7104$ would depend on variation in the numbers of cycles of replication of the phage in the various preparations.

Table 6. Phage titre of single plaques of phage $47 \mathrm{C} / 7104$ when plated on strains 7104 and Col.

\begin{tabular}{|c|c|c|c|}
\hline \multirow[b]{2}{*}{$\begin{array}{c}\text { Plaque } \\
\text { no. }\end{array}$} & \multicolumn{2}{|c|}{ Particles/plaque } & \multirow[b]{2}{*}{ Ratio $a / b$} \\
\hline & $\begin{array}{l}\text { On strain } 7104 \\
(a)\end{array}$ & $\begin{array}{c}\text { On strain } \mathrm{Col} \\
(b)\end{array}$ & \\
\hline 1 & $5.6 \times 10^{5}$ & $2.5 \times 10^{3}$ & 220 \\
\hline 2 & $2 \cdot 1 \times 10^{6}$ & $7.5 \times 10^{3}$ & 280 \\
\hline 3 & $1.5 \times 10^{6}$ & $3 \times 10^{3}$ & 533 \\
\hline 4 & $8 \cdot 3 \times 10^{5}$ & $5 \times 10^{3}$ & 166 \\
\hline 5 & $3.6 \times 10^{6}$ & $9.5 \times 10^{3}$ & 377 \\
\hline 6 & $2.5 \times 10^{6}$ & $1.3 \times 10^{4}$ & 192 \\
\hline 7 & $6.4 \times 10^{5}$ & $2.5 \times 10^{3}$ & 256 \\
\hline 8 & $5.4 \times 10^{5}$ & $3 \times 10^{3}$ & 180 \\
\hline 9 & $1.3 \times 10^{6}$ & $2.8 \times 10^{4}$ & 46 \\
\hline 10 & $3.9 \times 10^{5}$ & $3.2 \times 10^{4}$ & 112 \\
\hline
\end{tabular}

That the character of the host cell has an important effect on the nature of the phage propagated in it was further demonstrated when the lysogenic phage from propagating strains 7104 (47 C), 7167 (47 C) and 7296 (47 C) was examined. The phage $47 \mathrm{C}$ which had been introduced into these strains was present in broth cultures at titres of $10^{5}-10^{6}$ particles $/ \mathrm{ml}$. and showed plaques on propagating strains 7104,7167 or 7296 but not at all on propagating strains $\mathrm{Pa}$ or Col, having lost completely the ability to replicate in its former hosts.

By growing the phage in broth culture, the change in phage $47 \mathrm{C} / 7296$ in which ability was acquired to show plaques with equal efficiency on propagating strains 6 and 47 was found to occur in one cycle of replication. The cells of propagating strain 7296 were infected with phage $47 \mathrm{C} / \mathrm{Pa}$ (pure $\mathrm{A}$ ); the yield after one step and after complete clearing of the culture is given in Table 7 . After one step, equal phage counts were obtained on propagating strains 7296, $\mathrm{Pa}$, Col, 7104, 7167, 6 and 47. After several steps, the ability to form plaques on propagating strains $\mathrm{Pa}$, Col, 7104 and 7167 was diminished.

Variation in the lysogenic phage from strain $\mathrm{Col}$. When propagating strain $\mathrm{Col}$ was grown with aeration in glucose veal broth, large amounts of phage were released into the medium. This lysogenic phage was harvested after $2 \mathrm{hr}$. incubation and titrated on the series of indicator strains of staphylococci which were known to be sensitive to it. The titres (Table 8) varied from strain to strain, propagating strain Pa giving the highest count and propagating strains $7104,7167,7$, and $44 \mathrm{~A}$ giving similar counts. This lysogenic phage was then propagated from single plaques in propagating strains $\mathrm{Pa}, 7296,6,31 / 44,44 \mathrm{~A}$, 
and 47. The host range ratios of phages $\mathrm{Col} / \mathrm{Pa}$ and $\mathrm{Col} / 7296$ (Table 8 ) and the host ranges of the other four preparations (expressed in Table 9 by Williams \& Rippon's method) all indicate changes in the lytic spectra of the phage according to the hosts used for propagation. All phage preparations were serologically B. Phage Col/7296 behaved like phage $47 \mathrm{C} / 7296$ in that it showed plaques

Table 7. Change in host range of phage $47 \mathrm{C} / \mathrm{Pa}$ after one and after several cycles of replication in strain $\mathbf{7 2 9 6}$

\begin{tabular}{|c|c|c|c|c|c|c|}
\hline \multirow[b]{2}{*}{$\begin{array}{l}\text { Indicator } \\
\text { strain (IS) }\end{array}$} & \multicolumn{2}{|c|}{ Phage $47 \mathrm{C} / \mathrm{Pa}$} & \multicolumn{2}{|c|}{$\begin{array}{c}\text { One cycle in } \\
\text { strain } 7296\end{array}$} & \multicolumn{2}{|c|}{$\begin{array}{l}\text { Several cycles in } \\
\text { strain } 7296\end{array}$} \\
\hline & Plaques/ml. & $\begin{array}{l}\text { Ratio: } \\
\mathrm{Pa} / \mathrm{IS}\end{array}$ & Plaques/ml. & $\begin{array}{c}\text { Ratio: } \\
\text { 7296/IS }\end{array}$ & Plaques/ml. & $\begin{array}{l}\text { Ratio: } \\
\text { 7296/IS }\end{array}$ \\
\hline 7296 & $4 \times 10^{8}$ & 3 & $7.5 \times 10^{7}$ & 1 & $1.4 \times 10^{9}$ & 1 \\
\hline $\mathbf{P a}$ & $1.3 \times 10^{9}$ & $\mathbf{1}$ & $1 \times 10^{8}$ & 1 & $8 \times 10^{8}$ & 175 \\
\hline Col & $1.1 \times 10^{9}$ & $\mathbf{1}$ & $8 \times 10^{7}$ & $\mathbf{1}$ & $8 \times 10^{6}$ & 175 \\
\hline 7104 & $1.6 \times 10^{9}$ & $\mathbf{1}$ & $6 \times 10^{7}$ & 1 & $1.2 \times 10^{8}$ & 12 \\
\hline 7167 & $1.2 \times 10^{9}$ & 1 & $7 \times 10^{7}$ & 1 & $6 \times 10^{7}$ & 23 \\
\hline 6 & $6 \times 10^{7}$ & 20 & $6.5 \times 10^{7}$ & 1 & $7 \cdot 5 \times 10^{8}$ & $1 \cdot 8$ \\
\hline 7 & $2.6 \times 10^{6}$ & 500 & $1.3 \times 10^{4}$ & 6000 & $6 \times 10^{6}$ & 500 \\
\hline $31 / 44$ & $3 \times 10^{5}$ & 4000 & $5.5 \times 10^{4}$ & 1500 & $7 \times 10^{4}$ & 20,000 \\
\hline $44 A$ & $3 \times 10^{6}$ & 4000 & $5 \times 10^{4}$ & 1500 & $4.5 \times 10^{4}$ & 30,000 \\
\hline 47 & $1.8 \times 10^{7}$ & 70 & $7 \times 10^{7}$ & 1 & $1.6 \times 10^{9}$ & 1 \\
\hline
\end{tabular}

Table 8. Modifications of the host range of lysogenic phage from strain Col following its propagation in strains $\mathrm{Pa}$ and 7296

\begin{tabular}{|c|c|c|c|c|c|c|}
\hline \multirow[b]{2}{*}{$\begin{array}{l}\text { Indicator } \\
\text { strain }\end{array}$} & \multicolumn{2}{|c|}{$\begin{array}{l}\text { Phage Col on release } \\
\text { from strain } \mathrm{Col}\end{array}$} & \multicolumn{2}{|c|}{ Phage Col/Pa } & \multicolumn{2}{|c|}{ Phage Col/7296 } \\
\hline & Titre/ml. & $\begin{array}{l}\text { Ratio: } \\
\mathrm{Pa} / \mathrm{IS}\end{array}$ & Titre/ml. & $\begin{array}{l}\text { Ratio: } \\
\mathrm{Pa} / \mathrm{IS}\end{array}$ & Titre/ml. & $\begin{array}{l}\text { Ratio: } \\
\text { 7296/IS }\end{array}$ \\
\hline $\mathbf{P a}$ & $8 \times 10^{6}$ & & $2.4 \times 10^{8}$ & & $1.9 \times 10^{9}$ & 28 \\
\hline 7104 & $2 \times 10^{5}$ & 40 & c. $7 \times 10^{6 *}$ & c. $34^{*}$ & c. $5 \times 10^{8 *}$ & c. $100^{*}$ \\
\hline 7167 & $2 \times 10^{5}$ & 40 & c. $7 \times 10^{8 *}$ & c. 34* & c. $5 \times 10^{8 *}$ & c. $100^{*}$ \\
\hline 7296 & $2.5 \times 10^{6}$ & 3 & $8.5 \times 10^{7}$ & $2 \cdot 8$ & $5.5 \times 10^{10}$ & \\
\hline 6 & $9 \times 10^{4}$ & 90 & $1 \cdot 1 \times 10^{6}$ & 218 & $2.4 \times 10^{10}$ & $\mathbf{2 \cdot 3}$ \\
\hline 7 & $1.7 \times 10^{5}$ & 47 & $5.9 \times 10^{5}$ & 400 & $5 \cdot 2 \times 10^{8}$ & 100 \\
\hline $29 \mathrm{~A}$ & $1.5 \times 10^{2}$ & 50,000 & $1 \times 10^{4}$ & 29,000 & $5 \times 10^{8}$ & 10,000 \\
\hline $31 / 44$ & $4 \times 10^{5}$ & 20 & $6 \times 10^{5}$ & 400 & $5 \times 10^{7}$ & 1,000 \\
\hline $44 \mathrm{~A}$ & $1.8 \times 10^{5}$ & 44 & $2.5 \times 10^{5}$ & 960 & $1.6 \times 10^{8}$ & 340 \\
\hline 47 & $6.5 \times 10^{6}$ & 12 & $1.9 \times 10^{6}$ & 130 & $4.4 \times 10^{10}$ & $1 \cdot 3$ \\
\hline
\end{tabular}

more efficiently on propagating strains 6 and 47 than did the original phage. The results indicated that phages $47 \mathrm{C}$ and $\mathrm{Col}$ were both influenced in their host ranges by the cells in which they had been replicated. In cases where the phage could be transferred back to its original host it regained its previous lytic spectrum, indicating that the changes were phenotypic ones. In certain hosts, prolonged contact as prophage in the new host abolished completely the ability of the phage to attack former hosts. 
Table 9. Modification of the host range' of lysogenic phage Col, following its propagation in various hosts

\begin{tabular}{|c|c|c|c|c|}
\hline \multirow{2}{*}{$\begin{array}{l}\text { Indicator } \\
\text { strain }\end{array}$} & \multicolumn{4}{|c|}{ Phage } \\
\hline & $\mathrm{Col} / 6$ & $\mathrm{Col} / 31 / 44$ & $\mathrm{Col} / 44 \mathrm{~A}$ & $\mathrm{Col} / 47$ \\
\hline $\begin{array}{l}\mathrm{Pa} \\
7104\end{array}$ & $\begin{array}{c}+++ \\
-\end{array}$ & $\begin{array}{c}+++ \\
-\end{array}$ & $\begin{array}{c}+++t \\
-\end{array}$ & $\begin{array}{c}+++ \\
-\end{array}$ \\
\hline 7167 & - & - & - & - \\
\hline 7296 & $+t+t$ & ++ & $+t+t$ & $+t+t$ \\
\hline 6 & $+t+t$ & + & $+t$ & + \\
\hline 7 & ++ & \pm & ++ & \pm \\
\hline $31 / 44$ & ++ & ++++ & ++ & ++ \\
\hline $\mathbf{4 4 A}$ & $\stackrel{+}{+t+t}$ & - & $+++t$ & $\overline{-}++$ \\
\hline 47 & $+t+t$ & $+t+t$ & + & $+++t$ \\
\hline
\end{tabular}

$++t=$ confluent lysis. $+t=$ numerous plaques. $\quad+=10-20$ plaques. $\pm=<1-9$ plaques. $-=$ no plaques.

\section{Induction of a virulent mutant of phage Col}

As already described, when phages $47 \mathrm{C} / 7104$ and $47 \mathrm{C} / 7167$ were plated on propagating strain Col they showed poor efficiency in showing plaques, and these were small. However, some plaques were larger and clearer than others; such plaques were not found on propagating strain $\mathrm{Pa}$. When the contents of these plaques were examined serologically, they were found to consist of particles of serological group B. Three possible origins of this B phage were considered: (1) it was lysogenic phage derived from propagating strains 7104 or $7167 ;(2)$ it was a recombinant of phage $47 \mathrm{C} / 7104$ or $47 \mathrm{C} / 7167$ and the prophage of $\mathrm{Col}$; (3) it was a virulent mutant of $\mathrm{Col}$ prophage. If (1) were the correct explanation, phage capable of lysing propagating strain Col should be detectable in the supernatant fluids of propagating strains 7104 and 7167. Furthermore, stocks of phages $47 \mathrm{C} / 7104$ and $47 \mathrm{C} / 7167$ should contain the $B$ particles and treatment with anti-B serum before the phages were applied to plates of propagating strain Col should prevent the appearance of the $B$ plaques. No evidence of lysogenic phage capable of lysing propagating strain Col was found on repeated examination of the supernatant fluids of cultures of propagating strains 7104 and 7167.

Quantities $(0.1 \mathrm{ml}$.) of suspensions of phages $47 \mathrm{C} / 7104$ and $47 \mathrm{C} / 7167$ were mixed with $0 \cdot 1 \mathrm{ml}$. quantities of $10^{-2}$ dilutions of high titre anti-A and anti-B sera and with both sera. Control tubes containing only phage and broth were included. After incubation at $37^{\circ}$ for $90 \mathrm{~min} ., 0.01 \mathrm{ml}$. samples were spread on plates of propagating strains $\mathrm{Pa}$ and $\mathrm{Col}$. After incubation, no large plaques were found on the $\mathrm{Pa}$ plates. On propagating strain Col large and small plaques were present on plates which had been inoculated with the phage treated with anti-B serum and with the untreated phage; no plaques of any kind were present on the plates inoculated with phage pretreated with anti-A serum. The serology of a number of the large and small plaques was examined. The large plaques were $\mathbf{B}$; the small were $\mathbf{A}$; no plaques containing both types of particles were found. It was concluded that the $B$ phage was not present in the stocks of phages $47 \mathrm{C} / 7104$ and $47 \mathrm{C} / 7167$, but that it had arisen following 
contact of these phages with the Col cells. The fact that no mixed plaques were found ruled out the possibility of a recombination of phage $47 \mathrm{C}$ with the $\mathrm{B}$ prophage of strain Col. The most reasonable explanation of these findings was that the B phage had arisen by induction of a virulent mutant of $\mathrm{Col}$ prophage, analogous to the virulent mutant of $\lambda$ prophage of Escherichia coli, K 12 which is induced by ultraviolet irradiated $\lambda$ phage (Jacob \& Wollman, 1953). This explanation was supported by the findings that $B$ phage was not produced on the non-lysogenic $\mathrm{Pa}$ cells and that when $\mathrm{Pa}(\mathrm{Col})$ cells were used for plating the $\mathbf{B}$ phage was obtained.

Three other phages, $\mathrm{Col} / \mathbf{7 2 9 6}, 7104 / 31$ and 7104/47, showed what was probably the same inducing effect, the phage appearing on propagating strains $\mathrm{Col}$ and $\mathrm{Pa}(\mathrm{Col})$ but not on strain Pa. Since they were antigenically similar to the mutant serological prevention of induction could not be applied to them. However, evidence was not found that either of the propagating strains 7296, 31/44 or 47 carried phage capable of infecting strains Col or $\mathrm{Pa}$.

The host ranges of four preparations of the mutant phage of different origins made in propagating strain Col were identical (Table 10); they differed from those of phage Col. In particular, none produced plaques on propagating strain 7104, although $10^{-1}$ dilutions gave zones of inhibition such as described by Williams \& Rippon (1952) with some typing phages. The mutant phage often gave higher plaque counts on propagating strain $\mathrm{Pa}$ than on strain Col, suggesting that abortive infections occurred in cells containing the prophage which had been the origin of the mutant.

Table 10. Phage counts/ml. on various indicator strains of four separate preparations of the virulent mutant of prophage Col

\begin{tabular}{|c|c|c|c|c|}
\hline \multirow[b]{2}{*}{ Indicator strain } & \multicolumn{4}{|c|}{ Phage preparation } \\
\hline & $47 \mathrm{C} / 7104 / \mathrm{Col}$ & $\mathrm{Col} / 7296 / \mathrm{Col}$ & $7104 / 31 / \mathrm{Col}$ & $7104 / 47 / \mathrm{Col}$ \\
\hline Col & $3 \cdot 3 \times 10^{9}$ & $1.8 \times 10^{9}$ & $7.9 \times 10^{9}$ & $6.4 \times 10^{9}$ \\
\hline $\mathbf{P a}$ & $4.6 \times 10^{9}$ & $1.8 \times 10^{9}$ & $1 \times 10^{10}$ & $8.5 \times 10^{9}$ \\
\hline 7104 & Inhibition & Inhibition & Inhibition & Inhibition \\
\hline 7167 & $9 \times 10^{6}$ & $2.7 \times 10^{7}$ & $4.5 \times 10^{7}$ & $3 \times 10^{7}$ \\
\hline 7296 & $2 \cdot 3 \times 10^{8}$ & $1 \cdot 4 \times 10^{6}$ & $3 \times 10^{7}$ & $2.4 \times 10^{7}$ \\
\hline 6 & $1 \cdot 1 \times 10^{6}$ & $3 \times 10^{5}$ & $4.5 \times 10^{6}$ & $3 \times 10^{5}$ \\
\hline 7 & $1 \times 10^{7}$ & $1.4 \times 10^{6}$ & $3 \times 10^{6}$ & $2.5 \times 10^{8}$ \\
\hline $29 \mathrm{~A}$ & $1.8 \times 10^{5}$ & $1.5 \times 10^{5}$ & $4 \times 10^{5}$ & $3 \times 10^{5}$ \\
\hline 31 & $9 \times 10^{6}$ & $2 \cdot 9 \times 10^{6}$ & $3 \times 10^{7}$ & $1.7 \times 10^{7}$ \\
\hline $44 \mathrm{~A}$ & $7.5 \times 10^{6}$ & $1.8 \times 10^{6}$ & $5 \times 10^{6}$ & $5 \times 10^{6}$ \\
\hline 47 & $1.5 \times 10^{7}$ & $1.3 \times 10^{6}$ & $2 \times 10^{7}$ & $1.9 \times 10^{7}$ \\
\hline
\end{tabular}

Conditions under which the induced phage occurred appear to involve the application to Col cultures of a large number of phage particles which lack ability to be replicated in Col cells. The mutant was not detected when phages $47 \mathrm{C} / \mathrm{Pa}$ or $47 \mathrm{C} / 7296$ were plated on Col cells. The ratio of inducing phage to induced mutant is shown in Table 11. The case of phage Col/7296 was of particular interest since it indicated that, after replication of phage $\mathrm{Col}$ in propagating strain 7296, a small proportion of the particles were able to act as inducers of a mutant of the prophage from which they originally arose. 
Table 11. Ratio of inducing phage inoculated on strain Col to plaques of the mutant formed

$\begin{array}{cc}\text { Designation } & \text { Serology } \\ \text { Col } / 7296 & \text { B } \\ 47 \mathrm{C} / 7104 & \mathrm{~A} \\ 47 \mathrm{C} / 7167 & \mathrm{~A} \\ 7104 / 31 & \mathrm{~B} \\ 7104 / 47 & \mathrm{~B}\end{array}$

$\begin{array}{cc}\begin{array}{c}\text { No. of phage } \\ \text { particles inoculated }\end{array} & \begin{array}{c}\text { No. of B } \\ \text { plaques formed }\end{array} \\ (a) & (b) \\ 5.5 \times 10^{8} & 4 \\ 6 \times 10^{6} & 15 \\ 8 \times 10^{6} & 13 \\ 6 \times 10^{6} & 140 \\ 1.9 \times 10^{6} & 500\end{array}$

$$
\begin{gathered}
\text { Ratio } \\
a / b \\
1 \cdot 4 \times 10^{8} \\
4 \times 10^{5} \\
5 \times 10^{5} \\
4 \times 10^{4} \\
4 \times 10^{3}
\end{gathered}
$$

\section{DISCUSSION}

It is generally assumed that stocks (clones) of bacteriophages made from single plaques consist of genetically homogeneous populations of particles. However, mutations of host range and plaque morphology occur in many phages, e.g. the coli T phages (Luria, 1945) and phage $\lambda$ (Jacob \& Wollman, 1953), and phenotypic variation involving altered host range and dependent on the host, has been described in the coli-dysentery phages $\lambda$ and P 2 (Bertani \& Weigle, 1953), in coli phage T2 (Luria \& Human, 1952) and in Vi typing phages (Anderson \& Fraser, 1955). In the staphylococcal phages, interpretation of changes arising in phage clones is complicated by the almost universal lysogenicity of the cocci. The amount of lysogenic phage released by the host cells varies from strain to strain and many presumably pure phages may be contaminated in this way. Mutation of prophage to virulence during the synthesis of another phage or recombination of prophage with another phage during a lytic cycle are also possible events which might add to the complexity of phage stocks.

The present results suggest that the changes in host range of phages $47 \mathrm{C}$ and Col were due to modification of the particles by their host cells rather than to selection of mutants in the original phage stocks. In the phages grown in propagating strain 7296 which acquired ability to infect certain hosts the change occurred in one cycle of replication and can therefore be regarded as phenotypic. In those phages in which alterations in host range involved loss of ability to infect, there was evidence that the duration of contact of the particles with their new host determined the extent of this loss. In particular, long contact as the result of lysogenization caused profound alterations in the host range of the phage. In such cases, the selection of genotypic mutants during the propagation of the phage in its new host cannot be excluded with certainty.

One question of interest is whether prophage already present in a particular coccus may influence the character of another phage growing in the same organism. For example, cells of propagating strain 7296 carry a phage which lyses strongly propagating strains 6 and 47 , and phages $47 \mathrm{C}$ and Col both acquired similar lytic ability after passage through propagating strain 7296 , suggesting some interaction between the prophage and the lytic phage. On the other hand, propagating strains 7104 and $7 \mathbf{1 6 7}$ both carry phages which lyse propagating strains $31 / 44$ and 47 , but after phage $47 \mathrm{C}$ had been grown in these 
two strains it did not acquire any increased ability to attack strains $31 / 44$ or 47 . Perhaps the association found in propagating strain 7296 was fortuituous but there is the possibility that the prophage must be situated at a particular locus in the host cell before it can influence the character of other phages.

Williams Smith (1948) and Lowbury \& Hood (1953) showed that lysogenization of staphylococci altered their sensitivity to the typing phages. The present results confirm their observations and also indicate that the immunity conferred on a staphylococcal strain by a particular prophage may be either quite narrow and relate only to the lysogenizing phage or may extend to a number of phages. Which of these effects occur depends on the original typing pattern of the staphylococcus and this may be due to some intrinsic character of the strain as well as to its original lysogenic state.

Cross-immunity was not observed between phages of different antigenic structure but was found between phages which on serological and other grounds (usually host range) had been considered closely related. Many of the typing phages which differ only in their host ranges may, in fact, be phenotypic variants. The occurrence of reciprocal cross-immunity following lysogenization should therefore provide useful evidence of the identity of phages suspected of being closely related or identical.

The changes produced in phages $47 \mathrm{C}$ and $\mathrm{Col}$ by their transfer to different hosts have some application to the practice of phage typing of staphylococci. They illustrate the inadvisability of using any other than the standard strains for the propagation of phage stocks. The practice of testing with undiluted phages strains not lysed at the routine test dilution and of assuming, when lysis occurs, that it is due to the particular phage or phages applied, may need further consideration in the light of the finding that a virulent mutant of Col prophage could be induced by the application of a number of different phages. If such a phenomenon is of frequent occurrence, it would be unwise to assume that patterns obtained in typing by the application of high titre phages are due to the lysis of the host by these phages. Furthermore, some 'adapted' phages obtained by this method may be induced virulent mutants.

The apparent heterogeneity of the lysogenic phage released by Col cells poses a special problem. When serological differences are found between several lysogenic phages released by a particular staphylococcal strain, such as occur with phages belonging to group II (Rountree, 1949b), then multiple lysogenicity can be assumed. When, however, the differences are those of host range it may be incorrect to assume that distinct phages are present. Changes in host range occurred when the phage released in Col cultures was propagated in a variety of hosts. The available evidence suggests that these changes were phenotypic. The differences in efficiency in showing plaques revealed when the lysogenic phage in supernatant fluids of cultures of propagating strain Col was plated on the indicator strains may therefore be an expression of host differences rather than of differences in the released particles. In phage typing, differences in the degree of lysis caused by phages applied at their routine test dilutions are used as indications of host differences, but the exact significance and mechanism of reactions which vary from a few plaques to confluent lysis 
with a particular phage are still undetermined. Differences in efficiency in showing plaques of phage Col may be of similar nature. Further work is required to decide whether these differences are due to inhomogeneity of phage particles or to differences in the hosts. It seems likely, however, that the phenomena are of the same character as those in coli-dysentery phages discussed by Weigle \& Bertani (1953) who concluded that they arise from differences in the hosts.

This work was supported in part by the Australian National Health and Medical Research Council. My thanks are due to Dr Joan Rippon for a supply of anti-G phage serum.

\section{REFERENCES}

Anderson, E. S. \& Felix, A. (1953). The Vi type determining phages carried by Salmonella typhi. J. gen. Microbiol. 9, 65.

Anderson, E. S. \& Fraser, A. (1955). The influence of the factors determining Vitype specificity in Salmonella typhi on the adaptation of Vi-phage 11. J. gen. Microbiol. 13, 519.

Bertani, G. \& Weigle, J. J. (1953). Host controlled variation in bacterial viruses. J. Bact. 65, 113.

Fisk, R. T. (1942). Studies on staphylococci. II. Identification of Staphylococcus aureus strains by means of bacteriophage. J. infect. Dis. 71, 161.

JacoB, F. \& WollmanN, E. L. (1953). Induction of phage development in lysogenic bacteria. Cold Spr. Harb. Symp. quant. Biol. 18, 101.

Lowbury, E. J. L. \& Hoov, A. M. (1953). The acquired resistance of Staphylococcus aureus to bacteriophage. J. gen. Microbiol. 9, 524.

Luria, S. E. (1945). Mutations of bacterial viruses affecting their host range. Genetics, 30, 84.

Luria, S. E. \& Human, M. L. (1952). A nonhereditary, host-induced variation of bacterial viruses. J. Bact. 64, 557.

Lwoff, A. (1953). Lysogeny. Bact. Rev. 17, 269.

Ralston, D. J. \& Krueger, A. P. (1954). The isolation of a staphylococcal phage variant susceptible to an unusual host control. J. gen. Physiol. 37, 685.

Rippon, J. E. (1952). A serological variant of a staphylococcal typing bacteriophage. J.gen. Microbiol. 6, viii.

RounTREe, P. M. $(1949 a)$. The serological differentiation of staphylococcal bacteriophages. J. gen. Microbiol. 3, 164.

Kountree, P. M. (1949b). The phenomenon of lysogenicity in staphylococci. J. gen. Microbiol. 3, 153.

Rountree, P. M. (1952). Serological studies of the multiplication of a staphylococcal bacteriophage. Aust. J. exp. Biol. med. Sci. 30, 567.

Rountree, P. M. (1955). The role of divalent cations in the multiplication of staphylococcal bacteriophages. J. gen. Microbiol. 12, 275.

Weigle, J. J. \& Bertani, G. (1953). Variations des bactériophages conditionnées par les bactéries hôtes. Ann. Inst. Pasteur, 84, 175.

Williams, R. E. O.\& Rippon, J. E. (1952). Bacteriophage typing of Staphylococcus aureus. J. Hyg., Camb. 50, 320.

Williams Smrth, H. (1948). Investigations on the typing of staphylococci by means of bacteriophage. II. The significance of lysogenic strains in staphylococcal type designation. J. Hyg., Camb. 46, 82.

Wilson, G. S. \& Atkinson, J. D. (1945). Typing of staphylococci by the bacteriophage method. Lancet, i, 647 .

(Received 27 February 1956) 